\title{
Integrating Scrum development process with UX design flow
}

Nora Khaled Al Ghanmi, Nor Shahida Mohd Jamail

College of Computer and Information Sciences, Prince Sultan University, Saudi Arabia

\begin{tabular}{|c|c|}
\hline Article Info & ABSTRACT \\
\hline Article history: & \multirow{12}{*}{$\begin{array}{l}\text { Nowadays, Agile software development practices are being widely adapted } \\
\text { all over the world. Scrum is one of the most known Agile models, it satisfies } \\
\text { the business needs and put the main focus on the product. One common } \\
\text { challenge for the development of customer-facing products is having a good } \\
\text { user experience. This paper presents integrating Scrum development process } \\
\text { with user experience design flow. In this study, papers relating to the topic } \\
\text { of user experience (UX) process integration with Agile development process, } \\
\text { how to measure it and how to improve it, from the year } 2010 \text { onwards } \\
\text { are reviewed. This is to identify how organizations can integrate UX design } \\
\text { flow and Scrum development and get the benefits of both. The conducted } \\
\text { review identifies a number of limitations in the existing integrations efforts. } \\
\text { A proposed process model to resolve these limitations is presented. Along with } \\
\text { our experience in implementing it on an ongoing software development } \\
\text { project. The results of applying this process, its impact on the project } \\
\text { outcomes quality and the employees' satisfaction with the process are discussed. } \\
\text { The goal of this study is to aid organizations in integrating UX design into their } \\
\text { development process. }\end{array}$} \\
\hline Feb 28, 2020 & \\
\hline IVIat 1,2020 & \\
\hline Accepted Apr 13, 2020 & \\
\hline Keywords: & \\
\hline Agile & \\
\hline Scrum & \\
\hline Software development method & \\
\hline Software development process & \\
\hline elopment life cycle & \\
\hline & \\
\hline & \\
\hline
\end{tabular}

This is an open access article under the CC BY-SA license.

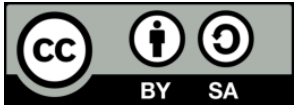

\section{Corresponding Author:}

Nora Khaled Al Ghanmi,

College of Computer and Information Sciences,

Prince Sultan University,

66833 Rafha Street, Riyadh 11586 Saudi Arabia.

Email: Alghanmi.nora@gmail.com

\section{INTRODUCTION}

Nowadays, Agile software development practices are being widely adapted all over the world [1]. This rapid adaption is due to agile methodology's ability to accommodate the current business needs. These business needs include rapid response change and a lower software development cost which can be achieved through Scrum model [2]. Scrum is one of the most known Agile models, it satisfies the business needs by aggregating the different developers' roles into cross functional Scrum teams [3]. Scrum merges the well-known development activities of gathering the requirements, designing the system, developing it and testing [4] into a minimal set of activities. Using Scrum has multiple advantages as it aligns the team, put the focus on the end product, and provide stakeholders with visibility on the project and the iterations it goes through.

Also, Scrum allows for a faster time to market [5] one requirement the business often have when the software is facing customers is the ease of use. Analyzing and designing the product for ease of use are often referred to as user experience (UX) design. UX designers work on studying the users' behaviors and needs then designing the software to make it easy to use and delightful for the users [6]. To do this they consider the users' feedback to address their satisfaction and increase it [7]. This includes the studying of their emotions [8] and mental model [9]. Companies are trying to address the user needs by integrating the UX design and making it part of developing their software. This led to UX designers being part of the Scrum team and needing to work within the sprints' time-box. However, UX design is very much 
a linear process which makes it hard to deliver a software that adhere to the best UX practices in a short time-boxed sprint and in an iterative manner [10]. The integration between UX and development sprint often caused clashes between their processes and lead to compromising on either quality or time. There is an identified lack of ideal process to integrate UX process and activities with the agile methodology [11]. UX design and Agile development are often needed together as the business need to delight the users and to ship the product faster. However, the different approaches and focus in the two processes makes it challenging to deliver the desired benefits together $[12,13]$. Multiple researchers have looked into integrating UX process with Agile development method. However, organizations still face a challenge when trying to choose and implement the best integration method. This paper presents integrating Scrum development process with UX design flow. A systematic review is conducted, followed by proposing a model to improve the integration and a case study for the proposed model. The aim of this study is to identify the challenges faced in the integration of the processes and identifying methods to resolve them.

\section{LITERATURE REVIEW}

This paper follows a systematic review process of the current work on integrating UX process with Agile development methodology, mainly Scrum model. Identifying the papers to be considered on the review was based on keywords using digital libraries. The keywords chosen are Agile \& User Experience, Scrum \& User Experience, HCI \& Agile or HCI \& Scrum. The publication date for the papers is from 2010 onward. This is to answer the review questions: What practices are currently being used? What challenges faces practitioners? What are the proposed or tried methods to resolve them? Are the current processes adequate? A total of 14 papers are identified for this study. They are organized under 3 main categories as shown in Table 1: reviewing the current state of the field, proposing a process model or proposing an evaluation technique. The papers in each of the 3 previously mentioned categories were analyzed to answer the research questions. We discuss each of these categories in the following sections.

Table 1. The papers reviewed

\begin{tabular}{|c|c|c|}
\hline Paper title & Year & Category \\
\hline Measuring effectiveness of HCI integration in software development processes [14] & 2010 & Proposing-Evaluation technique \\
\hline User experience design goes Agile in lean transformation-a case study [15] & 2012 & Reviewing-Case study \\
\hline $\begin{array}{l}\text { Agile development and user experience design integration as an ongoing achievement in } \\
\text { practice [16] }\end{array}$ & 2012 & Reviewing-Case study \\
\hline $\begin{array}{l}\text { Agile user experience development in a large software organization: Good expertise but } \\
\text { limited impact [12] }\end{array}$ & 2012 & Reviewing-Case study \\
\hline $\begin{array}{l}\text { Applying lean startup: An experience report-Lean \& lean UX by a UX Veteran: Lessons } \\
\text { learned in creating \& launching a complex consumer app [17] }\end{array}$ & 2012 & Reviewing-Survey \\
\hline $\begin{array}{l}\text { AGILEUXModel-Towards a reference model on integrating UX in developing software } \\
\text { using Agile methodologies [18] }\end{array}$ & 2014 & Proposing-Evaluation technique \\
\hline The prevalence of UX design in Agile development processes in industry [19] & 2015 & Rev \\
\hline $\begin{array}{l}\text { Overcoming challenges in Agile user experience work: Cross-case analysis of two large } \\
\text { software organizations [20] }\end{array}$ & 2015 & Reviewing-Case study \\
\hline $\begin{array}{l}\text { Integrating UX principles and practices into software development organizations: } \\
\text { A case study of influencing events [25] }\end{array}$ & 2019 & Reviewing-Case study \\
\hline
\end{tabular}

\subsection{Reviewing the current state of the field}

Multiple researchers tried to identify and address the challenges posed by integrating UX workflow and Scrum development. Each of them took a look at the integration challenges from a different angle. One cross case analysis [20] identified and addressed some of the challenges in integrating UX work and the development process. The researchers looked at two large software companies to address the challenges they faced. The highest challenge they faced is identifying and addressing the users' needs, followed by team alignment and managing the project big picture. As a result of their study they suggest including the UX specialist in the development team. More of the challenges related to the integration are identified in study [19]. It looked at the industry and the gaps between UX methods adapted by practitioners and what is being studied in academia. The focus was on identifying the methods used and challenges faced by practitioners. This was done by interviewing 8 companies twice. The interviews showed that $71 \%$ were using Scrum development process. On the other hand, $41 \%$ of the companies had UX work integrated in the Agile framework. The researchers suggested 2 approaches for integrating UX work 
into the agile framework. The first is training developers and letting them do the UX work. The second is altering the UX process to be more fitting with the development.

Another study [17] focused on reporting the practices adapted by organization workers relating to the integration of UX. The participants were developers and designers. Through this study they identified key points relating to the success of the integration. The mentioned points were relating to the behavior aspect which includes setting expectations of accepted behavior, mutual awareness and engaging with the other workers, and progress negotiating.

Moreover, multiple case studies in the topic were conducted. An empirical investigation of the integration of user centered design into the agile process for web development [21]. They conducted a case study with postgraduate students to evaluate the effectiveness of their proposed model. The case study showed an increased ability to detect and close defects faster. However, they faced a limitation in evaluating the effectiveness of the UX process due to the participant' limited experience with the required activities. Also, an explorative study [12] conducted a present state analysis concentrating on UX within Agile software development in a large software organization. They identified how the ineffective integration process negatively impacted the performance of the team which was mature in both areas but integrated wrongly.

Another case study [25] followed a group of practitioners for 15 months to understand their work and identify ways to help startups that want to adapt an agile process and integrate UX into it. The identified 5 main recommendations which are: to consider advices carefully before applying those, pay attention to UX work, be carefully when choosing technologies, optimize the development process and the team skills, and the last point is to test often and early. As time plays a factor in the integration one case study [16] focused on studying the changes in UX integration over time within an organization. They have identified the types of events overtime that affects the integration. These events could be categorized based on them being internal, direct, planned or the opposite. The challenges are also relatively similar for large organizations. A case study [15] was conducted in a large company that is ongoing a lean transformation process. The case study showed a difficulty in integrating UX process with lean Agile development process. The highest challenge they identified is that UX work is not very agile. The researchers point out the need to reconsider UX roles for successful integration. They also emphasize on the need for good communication between UX designers and developers.

\subsection{Proposing evaluation techniques}

Multiple processes were proposed to enhance the integration of UX process with the development process. Each of them tried to address the integration from a different angle. One study [10] discussed a model that integrates Agile development, design thinking and lean manufacturing. The integration resulted in lean UX model. They discuss applying lean manufacturing guidelines to eliminate waste. This waste elimination is done at the cost of interacting with the users and involving them during the design process as it is replaced by peer review of the designs.

Further enhancement on lean UX was proposed by a group of researchers [24]. They started by studying how the UX process integrates into Agile development in South African organizations. After identifying the commonly faced challenges they proposed a model that integrates lean UX process in Scrum framework. They added sprint 0 for the upfront UX work. Then the regular sprints included validating against the output from sprint 0 , sketching, presenting the sketches for feedback from the development. This process gets iterated within the sprint timebox. The output from the design sprint gets delivered for the consecutive development sprint.

Another research [22] proposed a model integrating the UX process and the development process. The proposed model was based on the unified process. They address the possibility of separating the front end and backend development. This is to deliver the front end needs first and postpone the backend until the design is mature and the usability needs are addressed. Also, on the integration one study [23] proposed a new work process that integrates user centered design with Scrumban. The intent is to benefit from the responsibility delegation and work breakdown features of Scrumban. This proposed model is aimed for small organizations. Scrumban roles are similar to Scrum but it utilizes the Kanban board. Organizing the work in Scrumban allow for the tasks to be started at anytime without being restricted to a sprint.

\subsection{Proposing a process model}

Two notable evaluation and measurements techniques for the integration were proposed. The first was preliminary maturity model aimed for small organization in alignment with MPS.BR, ISO18529 and CMMI [18]. The evaluation technique provided guidelines for mature, effective integration process. It focuses on having the integration separated into multiple iterations with the ability to prioritize the parts that are more critical to the company. The second technique focused on the integration effectiveness and how it is measured. They worked on identifying and addressing the difficulties related to measuring the effectiveness [14]. After that, they proposed a metric to measure the level of integration of human 
computer interaction activities in the overall software engineering process models and another to measure the product quality against its usability targets.

The integration between software development and UX design has been an area of interest and multiple researchers have identified some of the issues and proposed solutions for them. The proposed model had a common limitation which is the lack of emphasis on UX activities related to researching and testing. In the following section we propose a model that aims to address this limitation.

\section{RESEARCH METHOD}

This case study was conducted by proposing a model that integrates UX workflow and Scrum development practices to resolve the delivery time issue. The proposed process model was applied and tested with a team of 15 developer, product owner, system analyst, 2 testers, 2 UX designers, and 2 user interface (UI) designer. The results of this team were compared before and after using the proposed process. The proposed model efficiency is measured in terms of raised UX related defects after release and the time to market. This is followed by a survey to measure the team members satisfaction level with the process.

Before the experiment the team was following the well-known Scrum process. They started with adding the features as user stories to the product backlog then identifying a set of user stories to be added to the sprint backlog. During the sprint the development team including the UX and the UI designers take the stories in the sprint backlog and transform them into a working product as they see fit. This led to a large part of the development team, mainly the programmers and the testers setting idle at the beginning of the sprint with so little to work on. Also, the previous process was not ideal for the UX and UI designers as their work requires interacting with the users and iterating thorough the designs which would cause a delay.

In the proposed process model this is compensated by one large research at the beginning of the project with a sprint dedicated to it. Then throughout the project a smaller set of testing with the users are done as part of the design sprint which is separated from the development sprint. The design sprint should be one sprint ahead of the development sprint. In this study both of the processes were implemented by the same team. The set of features to be designed and implemented are estimated by the team to require similar level of effort in terms of both design and development.

\subsection{Proposed model}

The proposed model integrates Scrum development sprint with the UX workflow through an extended sprint model. The extended sprint model starts with a time boxed design sprint followed by a time boxed with the same duration development sprint. The outputs of design sprint 1 goes into the development sprint 1 as shown in Figure 1. During development sprint 1 the design team start sprint 2 to work on the next set of features. Also, the planning and grooming are attended by both designers and developers. Towards the end of the development the designers get involved to test the final product and if it conforms to the defined usability requirements.

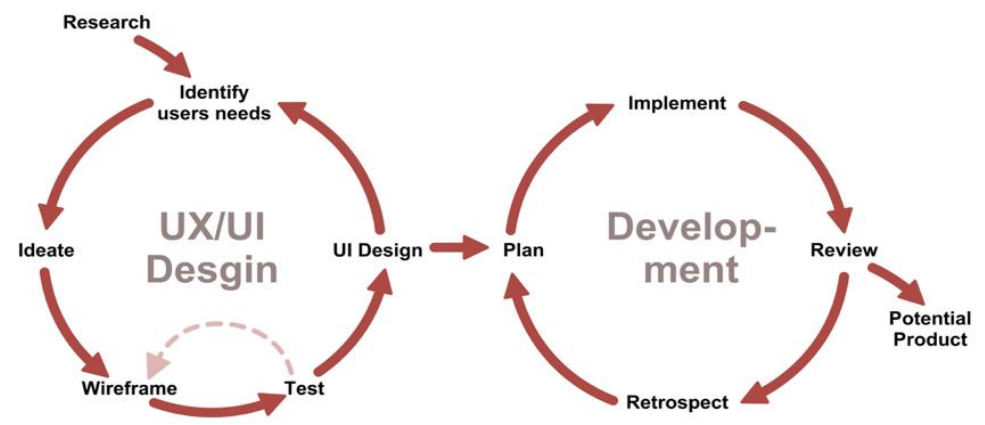

Figure 1. The proposed model

\subsubsection{Design sprint}

Before starting the sprint, the UX team works on conducting a largescale user research. The focus of this research is identifying the user's characteristics and behaviors and the drivers behind their actions. This will make the research findings more likely to be beneficial in supporting a wider set of design decision and able to support in designing unexpected features for the same target group. In addition to conducting the research, the team work on building the primary sections of design system with the components that will be commonly used such as the submit buttons and the input. The design system is a living artifact that grows 
and gets updated as the product grows. After this, the design sprint will begin with identifying what needs to be developed based on the user needs. Then, the team start the ideation to explore the problem in depth and identify a set of possible solutions. After that, they work on wireframing and having an initial version of the design to be reviewed with the development team to insure technical feasibility and available team capabilities. Then test the designs with the users to validate and improve them. The team iterate between wireframing and testing as needed within the sprint time box once the final wireframes are reached the teamwork on producing the user interfaces.

\subsubsection{Development sprint}

The development sprint starts with reviewing the sprint backlog which is at this step has been completed with the designs produced in the design sprint. Then they do the sprint planning with the help of the design team to clarify any ambiguities if there exist. During the sprint the development team organize itself and divide the tasks as they see fit. Then towards the end of the sprint they include the design team to check the usability of the features implemented and if there are any errors before proceeding to the review with the stakeholders. By the end of the sprint a review session is conducted for all interested parties. This is followed by the sprint retrospective meeting. During the retrospective the team identifies what went well, what went wrong and how to fix it in the following sprints.

\subsubsection{Ceremonies}

The process includes multiple ceremonies as shown on Table 2. These ceremonies consist of the common ceremonies identified in Scrum [26, 27]. Also, one additional meeting where the development team validate the designs and if they are implementable considering the current development team capabilities and timeframe.

Table 2. The process ceremonies

\begin{tabular}{|c|c|c|}
\hline Ceremony & Purpose & Participants \\
\hline Sprint planning & $\begin{array}{l}\text { Define the goal of the sprint and create the sprint } \\
\text { backlog }\end{array}$ & $\begin{array}{l}\text { Product owner, Scrum master, design team, } \\
\text { representative from the development team }\end{array}$ \\
\hline Daily standup & $\begin{array}{l}\text { To discuss progress in terms of what has been done and } \\
\text { what will be done. Also, if there any blockers to be } \\
\text { resolved by the Scrum master }\end{array}$ & $\begin{array}{l}\text { The design and development team. Scrum } \\
\text { master, product owner and stakeholders are } \\
\text { optional }\end{array}$ \\
\hline Development planning & $\begin{array}{l}\text { After the design part of the sprint is done and the } \\
\text { development is going to start, the team meet to plan } \\
\text { how to build the stories in the backlog }\end{array}$ & $\begin{array}{l}\text { Development team, product owner, Scrum } \\
\text { master and representative from the design } \\
\text { team }\end{array}$ \\
\hline Backlog grooming & $\begin{array}{l}\text { To assess the completeness of the stories, go over the } \\
\text { designs and assess the ability to implement them. }\end{array}$ & The entire Scrum team \\
\hline Review & $\begin{array}{l}\text { Inspect what went through the sprint and plan } \\
\text { improvement for the next sprint. }\end{array}$ & Scrum master, development and design team. \\
\hline
\end{tabular}

\section{RESULTS AND DISCUSSION}

After implementing the extended process model, we collected the data regarding the completion states of the stories and the bugs raised from the issue tracking tool used by the team "Jira". We can see from the presented results in Figure 2 that the number of reported bugs per 50 completed stories has went down from 23 to 6 bugs. This is due to extending the testing and including the UX designers in it which led to the majority of issues being identified before marking the stories as complete. Also, we can notice the improvement in the ratio of the stories completed and the ones moved back to the backlog after the end of the sprint, as the percentage of stories moved back has decreased by $75 \%$. However, the number of the stories completed changed only slightly. This indicates the increased teams' ability to estimate the number of stories they can complete within the sprint duration.

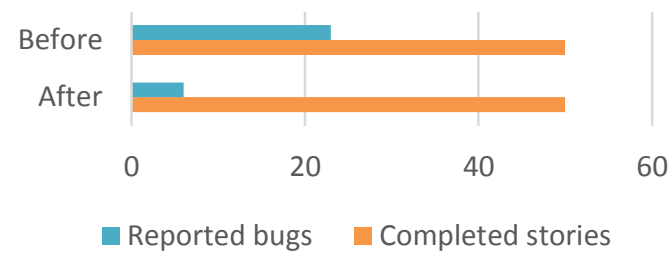

Figure 2. Bugs related to UX in production 
When it comes to the team's satisfaction, a survey asking the team members about their satisfaction and how comfortable they are working with the new process model. As seen on Figure 3 the majority of the developers (67\%) answered that they are comfortable working with the new process model. However, for the UI designers the survey shows they are not comfortable working in the new process model.

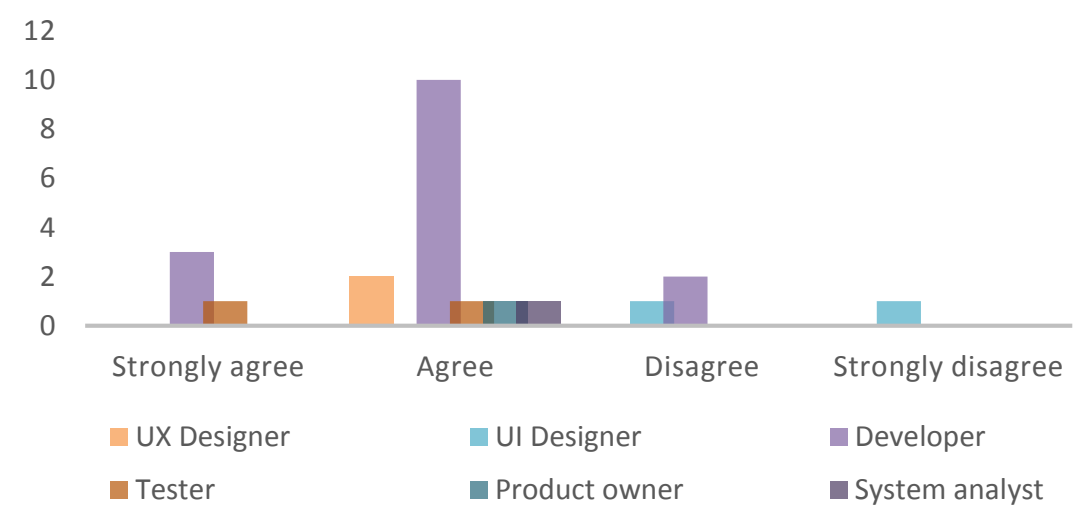

Figure 3. The team answers to "I feel comfortable working with the new process model"

\section{CONCLUSION}

During this paper, we looked into the existing work relating to the integration of UX design work flow with Scrum development process. We categorized the existing work into 3 groups, the first is reviews of what is implemented and researched, second is proposing new models and the third is proposing new measurements and evaluation techniques. Overall, there are challenges faced by organizations when trying to integrate the process. These include the nature of the activities in UX design and development and the lack of awareness. After that, we proposed process to integrate Scrum development and UX workflow. The process managed to address the problems of time and quality in design and development. However, it keeps the user research to the beginning which makes it only applicable for projects that do not require intensive research. In the future, we look to test the proposed process on a larger team over a longer period of time to insure its effectiveness.

\section{ACKNOWLEDGEMENTS}

This work was partially supported by the Artificial Intelligence Data Analytics Lab (AIDA), Prince Sultan University, Riyadh, Saudi Arabia.

\section{REFERENCES}

[1] M. Kunz, R. R. Dumke, and N. Zenker, "Software metrics for Agile software development," 19th Australian Conference on Software Engineering (aswec 2008), Perth, WA, pp. 673-678, 2008.

[2] M. Mahalakshmi and M. Sundararajan, "Traditional SDLC Vs Scrum methodology-a comparative study," International Journal of Emerging Technology and Advanced Engineering, vol. 3, no. 6, pp. 192-196, 2013.

[3] P. M. Ching and J. E. Mutuc, "Modeling the dynamics of an Agile Scrum team in the development of a single software project," 2018 IEEE International Conference on Industrial Engineering and Engineering Management (IEEM), Bangkok, pp. 386-390, 2018.

[4] B. A. Hutagaol, L. Abdilah, S. U. R. Jaya, and G. Wang, "Adoption of mobile smartphone attendance system based on case study of PT XYZ," Int. J. of Adv. Trends in Comp. Science and Eng., vol. 9, no. 1, pp. 21-25, 2020.

[5] A. Srivastava, S. Bhardwaj, and S. Saraswat, "SCRUM model for agile methodology," 2017 International Conference on Computing, Communication and Automation (ICCCA), Greater Noida, pp. 864-869, 2017.

[6] N. H. Basri, N. L. M. Noor, W. A. W. Adnan, F. M. Saman, and A. H. A. Baharin, "Conceptualizing and understanding user experience," 2016 4th International Conference on User Science and Engineering (i-USEr), Melaka, pp. 81-84, 2016.

[7] J. Zhang, E. Kamioka, and P. X. Tan, "Emotions detection of user experience (Ux) for mobile augmented reality (mar) applications," International Journal of Advanced Trends in Computer Science and Engineering, vol. 8, no. 1.4 S1, pp. 63-67, 2019.

[8] P. Kulkarni and T. M. Rajesh, "Analysis on techniques used to recognize and identifying the human emotions," International Journal of Electrical and Computer Engineering, vol. 10, no. 3, pp. 3307-3314, 2020. 
[9] K. C. Brata and A. H. Brata, "User experience improvement of japanese language mobile learning application through mental model and A/B testing," International Journal of Electrical and Computer Engineering (IJECE), vol. 10 , no. 3, pp. 2659-2667, Jun. 2020

[10] L. A. Liikkanen, H. Kilpiö, L. Svan, and M. Hiltunen, "Lean UX-The next generation of user-centered Agile development?," in Proceedings of the NordiCHI 2014: The 8th Nordic Conference on Human-Computer Interaction: Fun, Fast, Foundational, pp. 1095-1100, 2014.

[11] A. bin Deraman and F. A. Salman, "Managing usability evaluation practices in agile development environments," International Journal of Electrical and Computer Engineering (IJECE), vol. 9, no. 2, pp. 1288-1297, 2019.

[12] K. Kuusinen, T. Miikonen, and S. Pakarinen, "Agile user experience development in a large software organization: Good expertise but limited impact," Human-Centered Software Engineering (HCSE), Lecture Notes in Computer Science, Heidelberg, Berlin, vol. 7623, pp.94-111, 2012.

[13] A. Ogunyemi and D. Lamas, "Interplay between human-computer interaction and software engineering," 20149 th Iberian Conference on Information Systems and Technologies (CISTI), Barcelona, pp. 1-10, 2014.

[14] Joshi, N. L. Sarda, and S. Tripathi, "Measuring effectiveness of HCI integration in software development processes," Journal of Systems and Software, vol. 83, no. 11, pp. 2045-2058, 2010.

[15] M. Isomursu, A. Sirotkin, P. Voltti, and M. Halonen, "User experience design goes Agile in lean transformationa case study," 2012 Agile Conference, Dallas, TX, pp. 1-10, 2012.

[16] J. Ferreira, H. Sharp and H. Robinson, "Agile development and user experience design integration as an ongoing achievement in practice," 2012 Agile Conference, Dallas, TX, pp. 11-20, 2012.

[17] B. May, "Applying lean startup: An experience report-Lean \& Lean UX by a UX veteran: lessons learned in creating \& launching a complex consumer app," 2012 Agile Conference, Dallas, TX, pp. 141-147, 2012.

[18] L. Peres, T. S. D. Silva, F. S. Silva, F. F. Soares, C. R. M. D. Carvalho, and S. R. D. L. Meira, "AGILEUX model: Towards a reference model on integrating UX in developing software using Agile methodologies," 2014 Agile Conference, Kissimmee, FL, pp. 61-63, 2014.

[19] T. Øvad and L. B. Larsen, "The prevalence of UX design in Agile development processes in industry," 2015 Agile Conference, Washington, DC, pp. 40-49, 2015.

[20] K. Kuusinen, "Overcoming challenges in Agile user experience work: Cross-case analysis of two large software organizations," 201541 st Euromicro Conf. on Software Eng. and Adv. Applications, Funchal, pp. 454-458, 2015.

[21] P. Sfetsos, L. Angelis, I. Stamelos, and P. Raptis, "Integrating user-centered design practices into agile web development: A case study," 2016 7th Int. Conf. on Inf., Intell., Syst. \& Appl. (IISA), Chalkidiki, pp. 1-6, 2016.

[22] D. I. Sensuse, D. Satria, A. A. Pratama, I. A. Wulandari, M. Mishbah, and H. Noprisson, "Integrating UCD into Scrumban for better and faster usability design," 2017 International Conference on Information Technology Systems and Innovation (ICITSI), Bandung, pp. 297-302, 2017.

[23] A. Nasiri and H. Sadler, "UXUP-User eXperience centric unified process," 2018 IEEE International Conference on Engineering, Technology and Innovation (ICE/ITMC), Stuttgart, pp. 1-9, 2018.

[24] N. Pillay and J. Wing, "Agile UX: Integrating good UX development practices in Agile," 2019 Conference on Information Communications Technology and Society (ICTAS), Durban, South Africa, pp. 1-6, 2019.

[25] P. Kashfi, R. Feldt, and A. Nilsson, "Integrating UX principles and practices into software development organizations: A case study of influencing events," Journal of Systems and Software, vol. 154, pp. 37-58, 2019.

[26] V. T. Faniran, A. Badru, and N. Ajayi, "Adopting Scrum as an Agile approach in distributed software development: A review of literature," 2017 1st International Conference on Next Generation Computing Applications (NextComp), Mauritius, pp. 36-40, 2017.

[27] A. Srivastava, S. Bhardwaj, and S. Saraswat, "SCRUM model for agile methodology," 2017 International Conference on Computing, Communication and Automation (ICCCA), Greater Noida, pp. 864-869, 2017.

\section{BIOGRAPHIES OF AUTHORS}
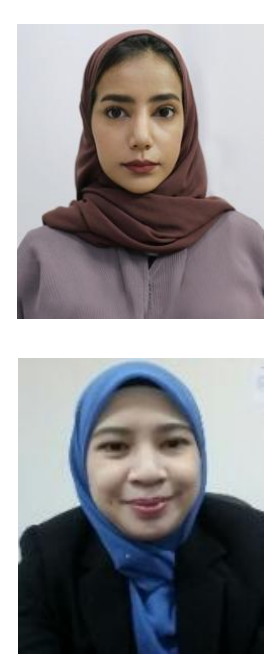

Nora Khaled Al Ghanmi is currently a Master of Software Engineering Student at Prince Sultan University. She obtained her bachelor's degree in Information Systems from Princess Norah University in 2018 and has been working in the field of software development since then.

Nor Shahida Mohd Jamail is currently in Prince Sultan University, Riyadh, Saudi Arabia as an Assistant Professor. She obtained her PHD in Software Engineering from Universiti Putra Malaysia. Her specialized are purely in Software Engineering, Software Process Modelling, Software Testing and Cloud Computing Services. She had involved in Machine Learning Research Group in Prince Sultan University and also involved in research project which collaborated with National and International University. Email: njamail@psu.edu.sa 